\title{
Impact of Different Stimulation Patterns of Neuromuscular Blockade Monitoring and Clinical Assessment on Intubation Time and Intensity of Hemodynamic Response During Rocuronium Induced Endotracheal Intubation
}

\author{
Radmilo J. Janković1,2, Milena D. Stojanović1,*,

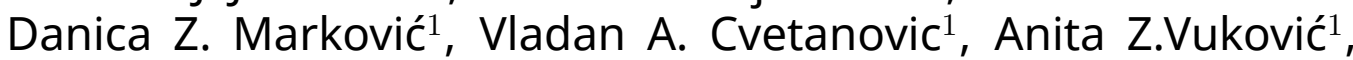 \\ Aleksandar N.Nikolić ${ }^{1}$, Ines S.Veselinović ${ }^{1}$, Biljana S.Stošić ${ }^{1,2}$
}

\author{
${ }^{1}$ Clinic for Anesthesiology and Intensive \\ care, Clinical Center Nis, Serbia \\ ${ }^{2} \mathrm{School}$ of Medicine, University of Nis, \\ Serbia

\section{*Correspondence} \\ milenastojanoviclaci@gmail.com \\ (Milena D. Stojanović)
}

\begin{abstract}
Introduction and aims: Typical autonomic response to endotracheal intubation manifests itself by increasing blood pressure and heart rate. The aim of this study as to evaluate whether different stimulation patterns of neuromuscular blockade monitoring techniques may impact hemodynamic response. Materials and Methods: Randomized, prospective, double blind study involved 60 patients who underwent elective abdominal surgery. Patients were randomly allocated into 3 groups. Anesthesia was induced with propofol-remifentanil and acceleromyography at adductor pollicis was established before rocuronium (0.6 $\mathrm{mg} / \mathrm{kg}$ ) was given to facilitate endotracheal intubation. Endotracheal intubation was initiated after 95\% suppression of $0.1 \mathrm{~Hz}$ single twitch (ST group), complete disappearance of responses to train-of-four stimulation (TOF group) or after clinical criteria (good relaxation of the masseter muscle and the lower jaw, easy mask ventilation and the fact that $60 \mathrm{secs}$ had elapsed since rocuronium was administered) were met (control-CL group). Blood pressure and heart rate were measured in five time points: after positioning the patient $\left(\mathrm{HD}_{\text {bas }}\right), 30 \mathrm{~s}$ after propofol-remifentanyl $\left(\mathrm{HD}_{1}\right), 30 \mathrm{~s}$ after rocuronium $\left(\mathrm{HD}_{2}\right), 30 \mathrm{~s}\left(\mathrm{HD}_{3}\right)$ and 2 minutes following initiation $\left(\mathrm{HD}_{4}\right)$ of endotracheal intubation. Results: The interval between administration of rocuronium and initiation of endotracheal intubation was significantly shorter in CL group (66.5 s), compared to TOF group (75.44 s) and ST group (83.75 s), ( $<<0.001)$. There was statistically significant difference in systolic blood pressure at HD3 and HD4 time point between groups ( $p$ $<0.01)$. Post hoc analysis shows that these values of systolic blood pressure in CL group were significantly higher compared to the other two groups $(\mathrm{p}<0.05)$. Also, systolic blood pressure after the fourth and fifth measurements were significantly higher compared to initial three measurements in CL group $(p<0.01)$. By comparing the heart rate at $\mathrm{HD}_{3}$ and $\mathrm{HD}_{4}$ time points, significant difference between the groups was noted $(\mathrm{p}<0.01)$. At $\mathrm{HD}_{3}$ time heart rate was significantly higher in CL group compared to other groups ( $\mathrm{p}<0.01$ ). Additionally, at $\mathrm{HD}_{4}$ heart rate was significantly higher in CL group than in TOF group $(p<0.05)$ and ST group ( $p<0.01)$. Also, heart rate was significantly increased at $\mathrm{HD}_{3}$ time point. Conclusion: Even though objective NMB monitoring prolongs intubating time, its use prevents vacillation of the hemodynamic response associated with endotracheal intubation.
\end{abstract}

\section{Keywords}

Neuromuscular blockade monitoring, Hemodynamic response, Intubation 
TA B L E 1. Examination of intubation conditions.

\begin{tabular}{lccc} 
Intubation conditions & \multicolumn{2}{c}{ Clinically acceptable } & \multicolumn{1}{c}{ Clinically unacceptable } \\
Indicator & excellent & good & bad \\
Laryngoscopy & easy & favorable & difficult \\
Vocal cords position & Abducted (please check the word) & Intermediate position & adducted \\
$\begin{array}{l}\text { Reaction to endotracheal tube } \\
\text { insertion } \text { or cuff insufflation }\end{array}$ & no & Light $\pi$ & sharp, sustainable \\
\hline
\end{tabular}

Laryngoscopy: Easy - lower jaw, relaxed, without resistance while introducing the laryngoscope, Favorable - lower jaw is not completely relaxed, slight resistance while introducing the laryngoscope, Difficult- bad relaxation of lower jaw, significant resistance while introducing the laryngoscope; "I one or two contractions or slight moves in a period shorter than 5 seconds; ${ }^{\Omega}$ more than two contractions or moves that are longer than 5 seconds.

TA B L E 2. Intubation conditions relative to the examined groups.

\begin{tabular}{lccc} 
Group & $\begin{array}{c}\text { Intubation conditions } \\
\text { unacceptable }\end{array}$ & Total \\
CL group & 10 & 10 & 20 \\
TOF group & 3 & 17 & 20 \\
ST group & $/$ & 20 & 20 \\
Total & 13 & 47 & 60 \\
\hline$\Omega$ examined & groups & according & to the intubation \\
conditions, Goodman and Kruskal test $(p<0.01$, \\
intensity 0.25).
\end{tabular}

\section{Introduction}

Since the curare was discovered, muscle relaxants have become an integral part of the word triad considering that they facilitate the laryngoscopy and endotracheal intubation, mechanical ventilation, reduce the need for anesthetics and facilitate surgical work [1-3].

Monitoring of neuromuscular blockade (NMB) is highly recommended during the entire duration of anesthesia, especially during induction and recovery. Whenever there is a need for the muscle relaxation in order to achieve clinically acceptable intubation conditions or to reduce the possibility of upper airway injury, this type of monitoring is preferable $[4,5]$. Although the peripheral nerve stimulator was found 50 years ago, only about $10 \%$ of anesthesiologists use the objective monitoring of neuromuscular blockade in everyday clinical practice $[6,7]$. Acceleromyography seems the most suitable.

The use of NMB monitoring is especially crucial during induction of anesthesia, in order to assess the optimal intubation time, ensure adequate conditions for intubation and reduce the hemodynamic response to laryngoscopy and tracheal tube insertion. Hemodynamic response to laryngoscopy and endotracheal intubation is one of major concern for anesthesiologist during induction of anesthesia. It is very well known that laryngoscopy and intubation, especially in conditions of light anesthesia and insufficient muscle relaxation, can cause an exaggerated hemodynamic response, manifesting itself as tachycardia and hyperten- sion [8]. Study by Chen et al. [9] showed that postintubation hypertension is associated with longer ICU stay and poor neurologic outcome in patients with severe traumatic brain injury. This activation of sympathetic nervous system could be harmful not only for patients with intracranial pathology but also in patient with coronary artery disease.

Nandi et al. [10] concluded that using NMB monitoring offer more satisfactory intubating conditions comparing to clinical judgement as well as attenuated hemodynamic response to laryngoscopy and intubation. Study of Witkowska et al. [11] showed that more time was required for intubation when NMB monitoring is used, but with better intubation conditions and minimal cardiovascular response.

\subsection{Aim}

The aim of the study was to determine how different stimulation patterns of neuromuscular blockade monitoring and clinical assessment of intubation time may impact the patient's hemodynamic response to laryngoscopy and tracheal tube insertion.

\section{Patients and methods}

Study conduction did not require the approval of the institutional ethical committee. The study was performed in the Department of Anesthesia and Intensive Care of the Clinical Center in Nis, Serbia in the period from November 2006 to December 2007. This randomized, prospective, double blind study was performed on 60 patients who underwent minor elective abdominal surgery. Patients were randomly allocated into three groups of 20 patients $(n=20)$. The first group of patients represented a control group (CL group, $n$ $=20$ ), in which clinical assessment of NMB was used. In the second group, the acceleropmyography, based on TOF stimulation pattern, was used (TOF group, $n=20$ ). Third group involved patients with acceleromyography $0.1 \mathrm{~Hz}$ single twitch monitoring (ST group, $\mathrm{n}=20$ ).

The inclusion criteria were based on the recommendation of the "Good clinical research practice in pharmacodynamic studies of neuromuscular blocking agents II: the Stockholm revision" [12] and according to declaration of Helsinki for 


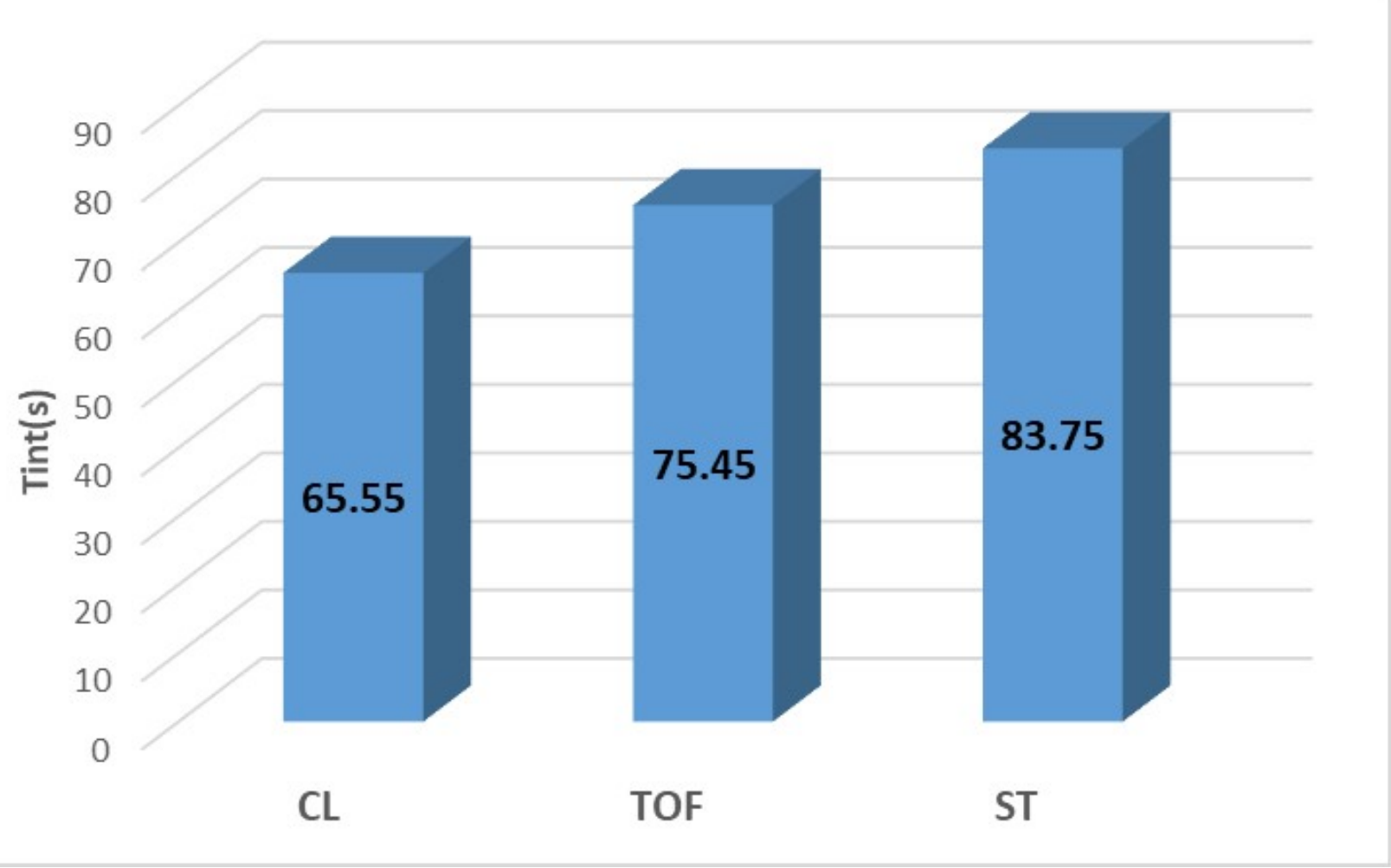

F I G U R E 1. Intubation time between different groups.

CL-control group, TOF- TOF group, ST-ST group;

$C L$ - control group (using clinical assessment of NMB); TOF- TOF group (using acceleromyography and TOF stimulation pattern); ST-ST group (using acceleromyography and single twitch stimulation pattern);

$p<0.001$ CL vs.TOF; * $p<0.001$ CL vs. ST; ${ }^{\#} p<0.001$ TOF vs. ST.

patient safety. The criteria were: patients older than 18 and younger than 65 , equal distribution by gender, BMI (body mass index) between 18.5 and $24.9 \mathrm{~kg} / \mathrm{m}^{2}$ and ASA I or ASA II (American Society of Anaesthesiologists) clinical status. The exclusion criteria were: the presence of manifest or latent co-existing neuromuscular disease, the presence of malignancy, hepatic or renal impairment of any degree, taking medications as $\mathrm{Ca}^{2+}$, blockers, aminoglycoside antibiotics or corticosteroids.

Patients were given midazolam $0.1 \mathrm{mg} / \mathrm{kg}$ i.m. (Dormicum ${ }^{\circledR}-$ Roche, Basel, Switzerland) as premedication. After positioning the patient, noninvasive hemodynamic monitoring was established [(pulse frequency - (f); non-invasive measurement of systolic and diastolic blood pressures - (SAP, DAP); mean arterial pressure - (MAP); pulse oximetry - $\left(\mathrm{SpO}_{2}\right)$; and monitoring of standard ECG leads)]. Baseline values of SAP, DAP, MAP, f and $\mathrm{SpO}_{2}\left(\mathrm{HD}_{\text {bas }}\right)$ were measured. The acceleromyograph, TOF Watch ${ }^{\circledR} \mathrm{S}$ (Organon Tehnika LTD, Dublin, Ireland) was placed on one arm, while the cuff for non-invasive measurement of blood pressure was set to the opposite site. Patients were pre-oxygenated with $100 \% \mathrm{O}_{2}$ via face mask for 3 minutes. For induction of anesthesia, remifentanil Minto TCI (Ultiva ${ }^{\circledR}$-Glaxo Smith Kline, Parma, Italy) and propofol Schnider TCI (Recofol $l^{\mathbb{R}}$-Shering, Schering Oy, Finland) were used targeting effect site concentrations of $4 \mathrm{ng} / \mathrm{ml}$ (Minto) and $2 \mu \mathrm{g} / \mathrm{ml}$ (Schnider) (BBraun Space Pump ${ }^{\circledR}$, Melsungen, Germany). After disappearance of palpebral reflex, the patients were ventilated with $100 \% \mathrm{O}_{2}$ via mask in order to maintain end-expiratory $\mathrm{CO}_{2} 30-35 \mathrm{~mm} \mathrm{Hg}$. The monitoring of the NMB was initiated after the induction and calibration of the acceleromyograph was done. In order to facilitate endotracheal intubation, rocuroniumbromide (Esmeron ${ }^{\circledR}-$ Organon, Oss, Holland) $0.6 \mathrm{mg} / \mathrm{kg}$ was given for 5 seconds. Anesthesia was maintained with total intravenous anesthesia targeting effect site concentrations of 4-8 $\mathrm{ng} / \mathrm{ml}$ for remifentanyl and 2-4 $\mu \mathrm{g} / \mathrm{ml}$ of propofol. For maintenance the muscle relaxation infusion of rocuronium-bromide was used at a dose of $0.3 \mathrm{mg} / \mathrm{kg} / \mathrm{h}$. Reversal was done with neostigmine 0.05 $\mathrm{mg} / \mathrm{kg}$ (Neostigmine ${ }^{\circledR}-$ RotexMedica, Trittau, Germany) and atropine was used at a dose of $0.015 \mathrm{mg} / \mathrm{kg}$ with the aim of neutralizing the unwanted effects of neostigmine.

For the subjective assessment of NMB the follow parameters were used: smoothness of the breathing bag, achievement of satisfactory tidal volume ( $>8 \mathrm{ml} / \mathrm{kg}$ ) without increasing the respiratory pressure and relaxation of the masseter muscle and the lower jaw 60 seconds after administration of rocuronium-bromide. For an objective assessment of the level of neuromuscular block the acceleromyograph was used, by stimulating n.ulnaris and 


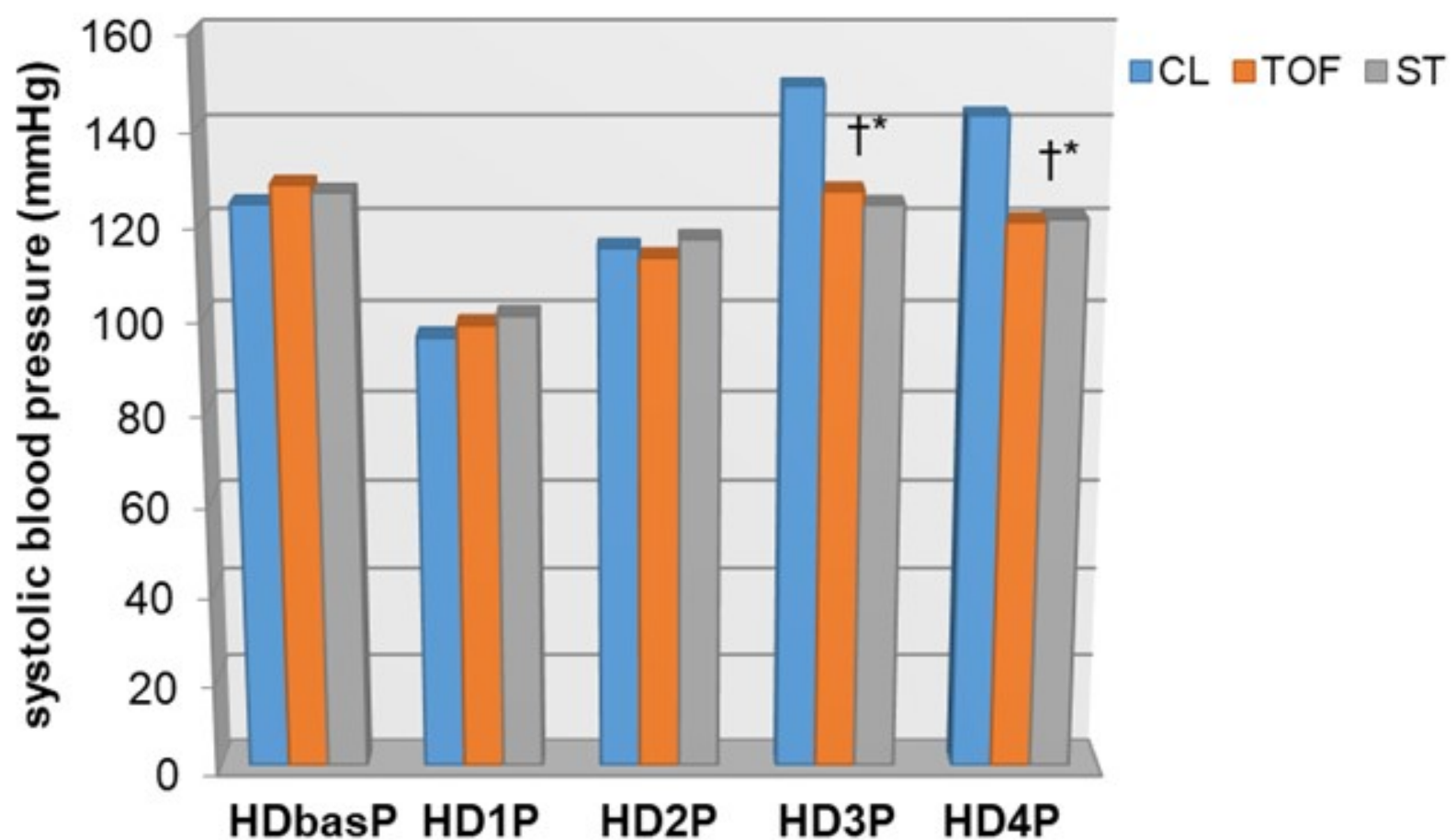

F I G U R E 2. The values of systolic blood pressure during control in the examined groups.

CL- control group, TOF- TOF group, ST-ST group;

$H D_{\text {bas }}$ - values of systolic blood pressure after positioning the patient on the operation table;

$H D_{1}$-the same values 30 seconds after administration of propofol and remifentanil;

$\mathrm{HD}_{2}$-the same values 30 seconds after administration of rocuronium-bromide;

$H_{3}$-the same values 30 seconds after the start of endotracheal intubation;

$\mathrm{HD}_{4}$-the same values 2 minutes after the start of endotracheal intubation.

${ }^{\dagger} p<0.05$ CL vs.TOF; *p $<0.05$ CL vs.ST.

measuring the response of m.adductor pollicis. In the second group of patients the intubation time was determined by the loss of all four responses to TOF stimulation mode, while in the third group of patients the weakening of the answer to $0.1 \mathrm{~Hz}$ ST stimulation mode was followed. After the $95 \%$ of the $T_{1}$ suppression, the anesthesiologist began with intubation $\left(\mathrm{T}_{1} / \mathrm{T}_{0}<5 \%\right)$. Intubation time $\left(\mathrm{T}_{\text {int }}\right)$ was the time from the beginning of rocuronium-bromide administration to the moment of intubation. The time limit for intubation, including the rigid laryngoscopy and endotracheal intubation accounted for 20 seconds. The patients in which this process was longer than mentioned above, the patients in which intubation was not possible, as well as the patients who were intubated after several attempts were excluded from further investigation.

The parameters that were evaluated for determining the quality of intubation conditions were: easiness of laryngoscopy, position and/or mobility of the vocal cords and the reaction to endotracheal intubation (Table 1. Examination of intubation conditions). The quality of intubation conditions was estimated by anesthesiologists who were unaware of the study protocol and who performed endotracheal in- tubation, based on the statement of Stockholm revision of Good Clinical Research practice in pharmacodynamic studies of neuromuscular blocking agents II [12].

To assess the correlation between the performance of NMB and hemodynamic response to intubation in patients of all three groups were measured systolic blood pressure and heart rate in the following intervals: 1) after positioning the patient on the operation table $\left(\mathrm{HD}_{\text {bas }}\right)$; 2) 30 seconds after administration of propofol and remifentanil $\left(\mathrm{HD}_{1}\right)$; 3) 30 seconds after administration of rocuronium-bromide $\left(\mathrm{HD}_{2}\right)$; 4) 30 second after the start of endotracheal intubation $\left(\mathrm{HD}_{3}\right)$ and 5) 2 minutes after the start of endotracheal intubation $\left(\mathrm{HD}_{4}\right)$. 


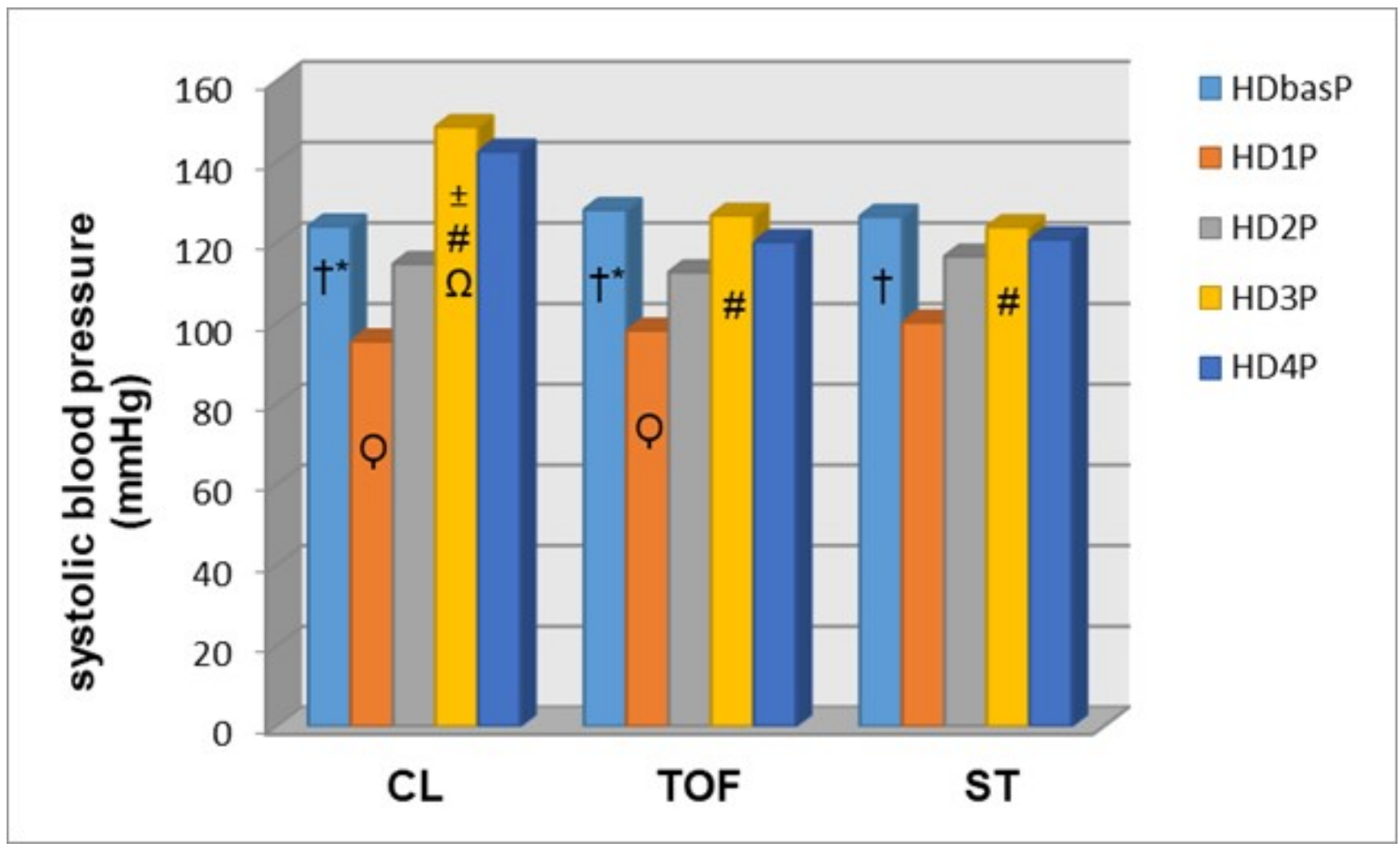

F I G U R E 3. The values of systolic blood pressure in the examined groups during follow-up.

CL-control group, TOF- TOF group, ST-ST group;

$H D_{b a s}$ - values of systolic blood pressure after positioning the patient on the operation table;

$H D_{1}$-the same value 30 seconds after administration of propofol and remifentanil;

$\mathrm{HD}_{2}$ - the same value 30 seconds after administration of rocuronium-bromide;

$\mathrm{HD}_{3}$ - the same value 30 seconds after the start of endotracheal intubation;

$H D_{4}$ - the same value 2 minutes after the start of endotracheal intubation;

${ }^{\dagger} p<0.01 H D_{b a s} P$ vs $H D_{1} P ; * p<0.05 H D_{b a s} P$ vs $H D_{2} P ; p<0.05 H D_{1} P$ vs $H D_{2} P ;{ }^{ \pm} p<0.01 H D_{3} P$ vs $H D_{b a s} S ;{ }^{\# p}<$ $0.01 \mathrm{HD}_{3} \mathrm{P}$ vs $H D_{1} P ;{ }^{\Omega} \mathrm{HD}_{3} P$ vs $H D_{2} P$.

\section{Results}

This study included 60 patients, which were divided into three groups of 20. All patients were between 19 and 65 years of age $(47.03 \pm 11.27)$. Thirty patients were female $(50 \%)$ and 30 were male $(50 \%)$. From a total of 60,31 patients (51.66\%) belonged to ASA I group, and 29 (48.33\%) were ASA II group. In 29 patients (48.3\%) laparoscopic or open cholecystectomy was done, 19 patients $(31.7 \%)$ were operated on for hernia of the anterior abdominal wall, and 12 patients $(20 \%)$ were operated on for appendicitis.

\subsection{Comparison of monitoring techniques and time of intubation}

Intubation time $\left(\mathrm{T}_{i n t}\right)$ in $\mathrm{CL}$ group was $65.55 \pm 4.44 \mathrm{~s}$ (range $61-77 \mathrm{~s}$ ), in the TOF group $\mathrm{T}_{\text {int }}$ was $75.45 \pm 7.50$ (range $65-88 \mathrm{~s}$ ), while in the ST group was $83.75 \pm 6.08 \mathrm{~s}$ (range 69-96 s). Intubation time was statistically different ( $\mathrm{p}<0.001)$. (Fig. 1. Intubation time between different groups).

\subsection{Comparison of the influence of monitoring techniques on intubation conditions}

The number of unacceptable conditions is decreasing and number of acceptable increasing starting from CL group over the TOF group to the ST group. For examining the significance of this connection, a nominal bidirectional Goodman and Kruskal tau test was used. Test showed a significant influence of the examined group on the intubation conditions $(\mathrm{p}<0.01)$, with the intensity of connection 0.25 . (Table 2. Intubation conditions relative to the examined groups).

\subsection{Comparison of monitoring techniques and intensity of hemodynamic responses to endotracheal intubation}

Difference in systolic blood pressure between the groups for each individual measurement was tested by ANOVA test. The results showed that there was no statistically significant difference in the values of pressure, regardless of the group of patients, both in the basal as well as the first and second 


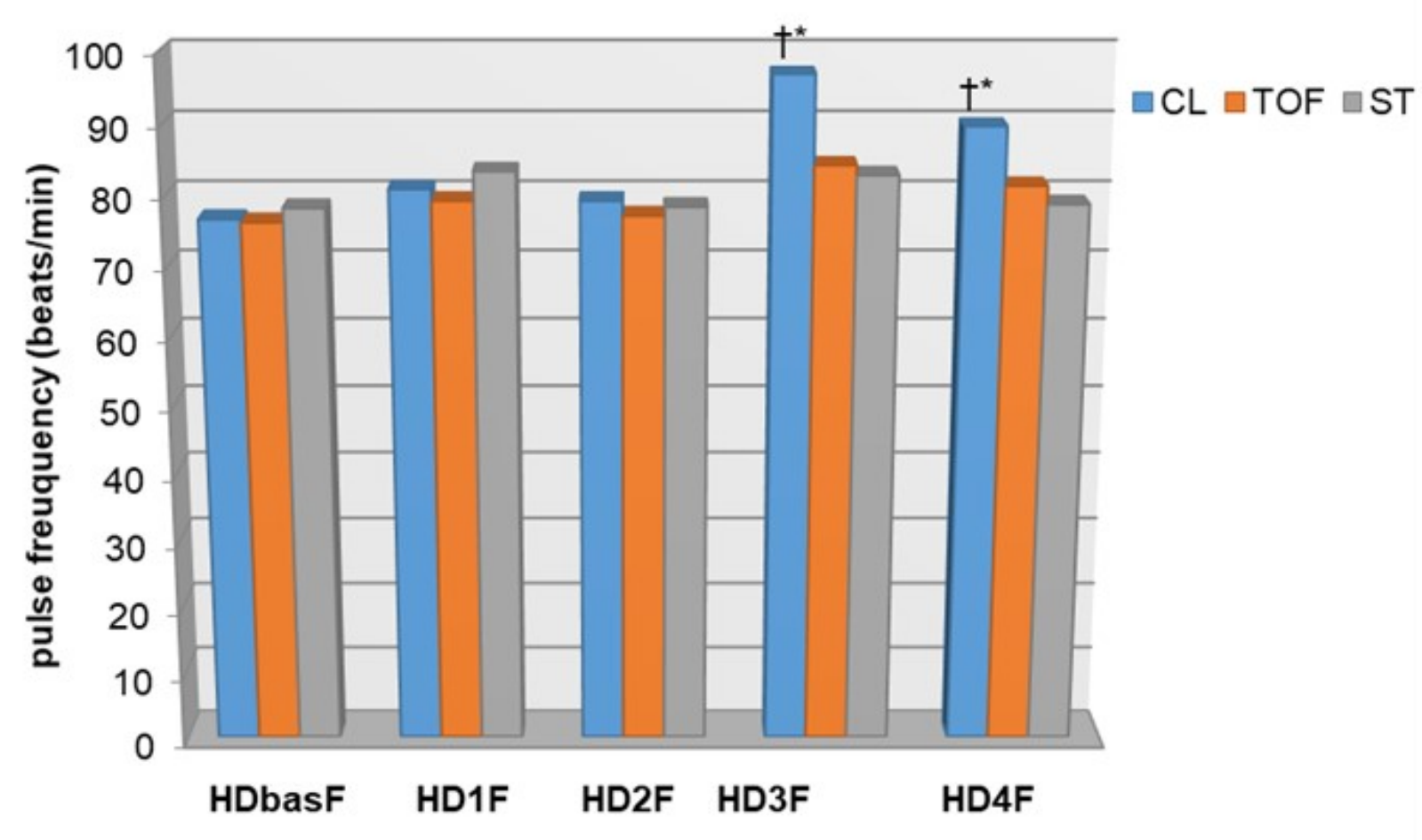

F I G U R E 4. The values of pulse frequency during the measurement interval in relation to the examined groups. CL- control group, TOF- TOF group, ST-ST group;

$H D_{\text {bas }}$ - values of pulse frequency after positioning the patient on the operation table;

$H D_{1}$-the same values 30 seconds after administration of propofol and remifentanil;

$H D_{2}$ - the same values 30 seconds after administration of rocuronium-bromide;

$H_{3}$ - the same values 30 seconds after the start of endotracheal intubation;

$H D_{4}$ - the same values 2 minutes after the start of endotracheal intubation;

$H D_{3} F^{\dagger} p<0.01 C L$ vs. TOF, ${ }^{*} p<0.05 C L$ vs. ST; $H D_{4} F^{\dagger} p<0.05 C L$ vs. TOF, ${ }^{*} p<0.01 C L$ vs. ST;

CL- control group, TOF- TOF group, ST-ST group.

measurements. However, the blood pressure values were significantly different between the groups after the third and fourth measurement $(\mathrm{F}=6.73, \mathrm{p}<0.01$ and $\mathrm{F}=9.18, \mathrm{p}<$ 0.01 prospectively). The Post hoc analysis with the Tuckey $H S D$ test showed that after the third measurement value of systolic blood pressure in the CL group was significantly higher than in the other two groups $(p<0.05)$, while the value of systolic blood pressure between these two groups (TOF and ST groups) had no difference. The same analysis showed that after the fourth measurement, values of pressure were also significantly higher in CL group compared with other two groups $(p<0.05)$, whereby the pressure values between the last two groups did not differ significantly (Fig. 2. The values of systolic blood pressure during control in the examined groups).

Analysis of variance showed that there were significant differences in the level of systolic blood pressure during control measurements, regardless of the group $(\mathrm{F}=6.8, \mathrm{p}$ $<0.01)$. In all three groups post hoc analysis performed showed that there was a significant pressure drop after the first measurement $(\mathrm{p}<0.01)$. However, in $\mathrm{CL}$ and TOF groups these values remain significantly lower during the second measurement $(\mathrm{p}<0.05)$, while in ST group returned to the previous values. The values of systolic blood pressure after the third and fourth measurements in CL group were significantly higher than the basal and the first two measurements $(\mathrm{p}<0.01)$, while these values in TOF and ST groups were at the basal levels (Fig. 3. The values of systolic blood pressure in the examined groups during follow-up).

The performed ANOVA test did not show a significant difference in the pulse frequency regardless of the group of patients at the basal as well as at the first and the second control measurements. But the values of pulse frequency between different groups are significantly different after the third and fourth measurements $(\mathrm{F}=6.4, \mathrm{p}<0.01$ and $\mathrm{F}=5.4, \mathrm{p}<0.01$ prospectively). Subsequent post hoc analysis with Tuckey HSD test showed significantly higher values after the third pulse frequency measurements in $\mathrm{CL}$ group compared with the other two groups $(p<0.01)$, while the pulse frequency between TOF and ST groups did not differ significantly. Also, the pulse frequency in CL group was significantly higher even after fourth measurement in relation to TOF $(\mathrm{p}<0.05)$ and ST group $(\mathrm{p}<0.01)$, while 


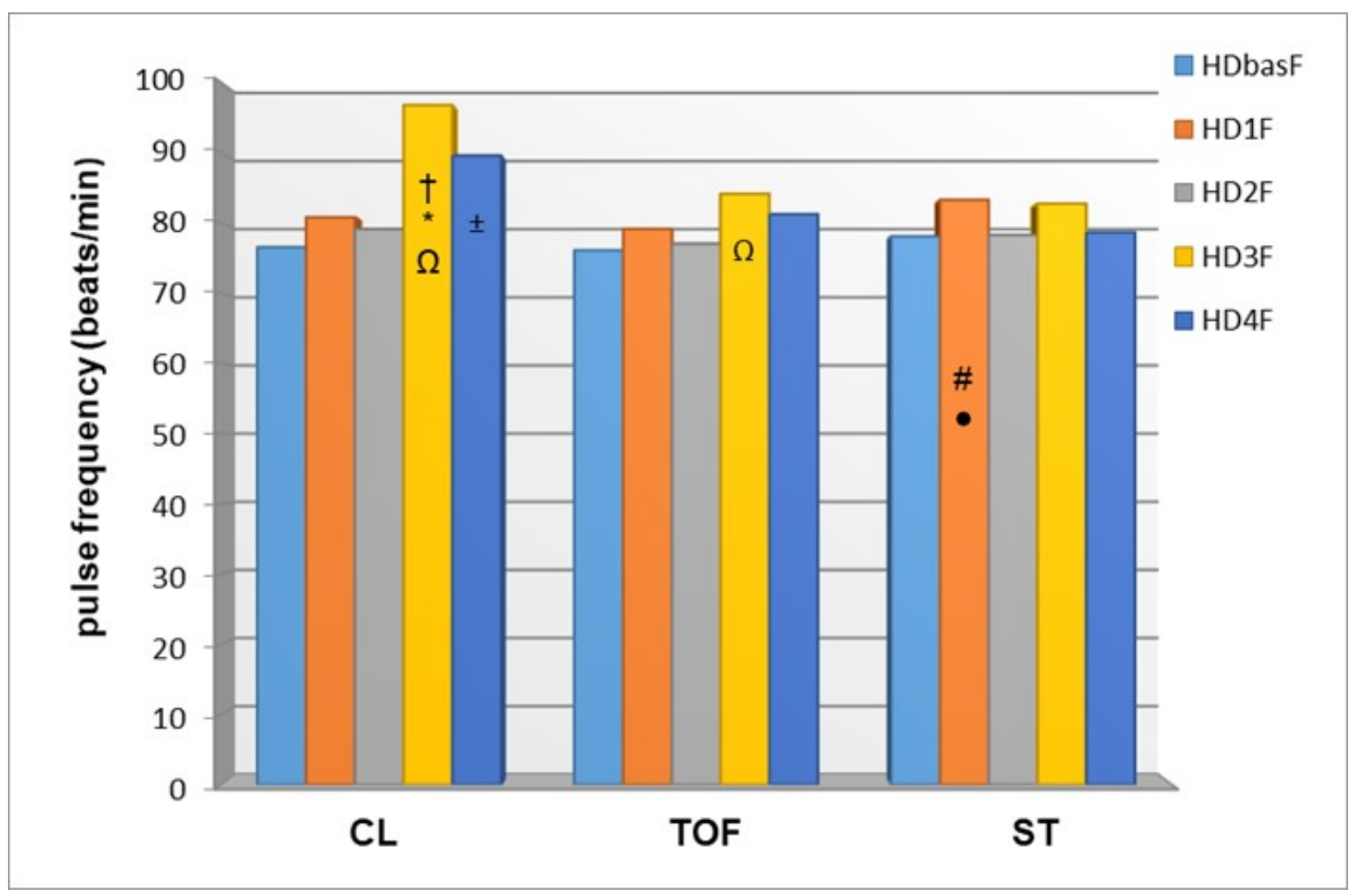

F I G U R E 5. The values of pulse frequency within the group in relation to different measurement intervals. CL- control group, TOF- TOF group, ST-ST group;

$H D_{\text {bas }}$ - values of pulse frequency after positioning the patient on the operation table;

$H D_{1}$-the same values 30 seconds after administration of propofol and remifentanil;

$H D_{2}$ - the same values 30 seconds after administration of rocuronium-bromide;

$H D_{3}$ - the same values 30 seconds after the start of endotracheal intubation;

$H_{4}$ - the same values 2 minutes after the start of endotracheal intubation.

${ }^{\dagger} p<0.05 H D_{3} F$ vs. $H D_{\text {bas }} F ;{ }^{*} p<0.05 H d_{3} F$ vs. $H D_{1} F ;{ }^{\Omega} p<0.05 H D_{3} F$ vs. $H D_{2} F ;{ }^{ \pm} p<0.05 H D_{4} F$ vs. $H D_{\text {bas }} F$;

${ }^{\#} p<0.05 H D_{1} F$ vs. $H D_{\text {bas }} F ; \bullet p<0.05 H D_{1} F$ vcs. $H D_{2} F$.

the values of a pulse frequency between these two groups did not differ significantly (Fig. 4. The values of pulse frequency during the measurement interval in relation to the examined groups).

ANOVA test showed a significant difference in values between the different measurements of pulse frequency in $\mathrm{CL}$ group $(\mathrm{F}=8.07, \mathrm{p}<0.01)$. Subsequent post hoc analysis showed that the value of pulse frequency after the third measurement was significantly higher compared to the basic and first two measurements $(p<0.05)$. After the fourth measurement, the values of pulse frequency were significantly higher only in relation to the baseline, but without a significant difference in comparison to other two measurements. In the TOF group a significant difference in the values of pulse frequency after the different measurements was also present $(\mathrm{F}=2.76, \mathrm{p}<0.05)$, while the post hoc analysis revealed a significantly higher value of pulse frequency in the third measurement compared with baseline value, whereas other measurement values showed no significant difference. In the STgroup ANOVA test showed significant differences during different measurements $(\mathrm{F}=4.2, \mathrm{p}<0.01)$. In this group the values of pulse frequency after the first measurement were signifi- cantly higher than the frequency of pulse after the basic and second control measurement $(\mathrm{p}<0.05)$, while the other pulse frequency measurements did not differ significantly during the measurement periods (Fig. 5. The values of pulse frequency within the group in relation to different measurement intervals).

\section{Discussion}

Although over 50 years have passed from the discovery of the peripheral nerve stimulator, its infrequent use in everyday clinical practice is more than evident $[7,13,14]$.

Rocuronium is a new steroidal, non-depolarizing muscle relaxant with rapid onset and intermediate duration of action. The reason for its rapid onset of action may be associated with its potency [15]. Namely, the less potent drugs require higher concentrations in blood to achieve neuromuscular block [16] leading to faster occupancy of receptors and faster achieving of neuromuscular blockade. This matches with other authors who suggest that the higher intubation dose of rocuronium is responsible for rapid onset of action, and that the diffusion gradient between plasma and pre/postsynaptic receptors is higher in comparison with 
other more potent neuromuscular relaxants [17]. Some other authors claim that the faster onset of action of rocuronium is conditioned by the less binding to the plasma proteins compared with pancuronium or vecuronium [18]. The standard intubation dose of $0.6 \mathrm{mg} / \mathrm{kg}\left(2 \times \mathrm{ED}_{95}\right)$ provides good or excellent intubation conditions in 60-90 seconds. Increasing the dose to $0.9-1.2 \mathrm{mg} / \mathrm{kg}$ reduces the onset of action (45-60 seconds), so it can be used when it is necessary to provide adequate intubation conditions in a short period of time [19].

The onset of action of muscle relaxant in part depends on the speed by which it arrives at the neuromuscular junction, which depends on cardiac output and blood flow through the muscles. Using ketamine [20] or etomidate [21], which maintain cardiac output and blood pressure, provides shorter onset of action and better intubation conditions. Since propofol reduces blood pressure and blood flow through the muscles, this may lead to a slower onset of action of muscle relaxants [20]. Different studies have shown that the addition of ephedrine can prevent a drop in blood pressure, allowing better muscle perfusion and faster onset of neuromuscular blockade when succinylcholine [22], cisatracurium [23] and vecuronium [24] are used. Study by Sing $\mathrm{H}$ et al. showed that addition of ephedrine when propofol is used leads to better intubation conditions, enabling faster delivery of rocuronium to the diaphragm and laryngeal muscles [25].

During the induction in anesthesia acceleromyography is particularly suitable for assessing adequate intubation time. To achieve good or even excellent intubation conditions, and reduce the possibility of occurrence of the trauma, it is necessary to achieve adequate muscle relaxation of the jaw, laryngeal, pharyngeal muscles and the diaphragm [26].

In our study, the onset of action for rocurnium was accounted for 61-96 seconds in study groups. Intubation time was significantly different in terms of the type of neuromuscular monitoring used. In patients in whom the neuromuscular monitoring was subjectively assessed, intubation time was 65.55 seconds, with intubation range of 6177 seconds. In the group of patients where acceleromyography was used, favorable intubation conditions occurred much later (TOF group- 74.45 seconds and ST group- 83.75 seconds).

Hemodynamic response to rigid laryngoscopy and endotracheal intubation involves reflex sympathetic stimulation accompanied by increase in levels of endogenous catecholamines and stimulation of cardiovascular system. If intubation is performed under deep anesthesia, the hemodynamic response is less pronounced. Increased hemodynamic response is due to stimulation of epipharynx and larynx. Acceleration of the heart rate is especially evident during laryngoscopy, and the pulse frequency does not decline despite increased blood pressure. The level of adrenalin and noradrenalin rises 2 and 5 minutes after the start of intubation in particular, the level of vasopressin increases very little, while the levels of dopamine and angiotensin-converting enzyme do not change [7, 27].
Response of the cardiovascular system depends of the duration of laryngoscopy, which is especially expressed when laryngoscopy takes longer than 30 seconds [28]. The increase in heart rate during laryngoscopy and intubation, in relation to the time before induction, is higher for about 20-25 beats per minute. The type of laryngoscope is also important. Using a Macintosh laryngoscope leads to a greater increase in heart rate compared to McCoy, and this is a result of pressure to the soft tissues in the front of epiglottis [29, 30]. Patients in our study in whom the intubation was longer than 20 seconds, were excluded from further investigation.

Some techniques and drugs are used to attenuate hemodynamic response during intubation, such as a deeper level of anesthesia, the use of opioids, beta blockers, intravenously lidocaine or magnesium-sulfate [31]. Among the opioids, remifentanil is particularly suitable in continuous infusion because its high clearance and low volume of distribution, resulting in rapid recovery after prolonged infusions [32]. Hemodynamic response can be successfully reduced with $1 \mu \mathrm{g} / \mathrm{kg}$ remifentanil as a bolus dose $[33,34]$, which coincides with the dose used in our study.

Our results showed the expected drop in systolic blood pressure 30 seconds after the administration of propofol and remifentanil, which amounted $30 \%$ on average. Average systolic blood pressure after induction was significantly different as well from the basal values as from other measurements in all three groups. After the induction with remifentanil and propofol, we observed a statistically significant decrease in blood pressure which was not accompanied by compensatory increase in heart rate. A possible reason may be extremely parasympathetic effect of remifentanil. Beside the attenuation of hemodynamic response, opioids provide better intubation conditions [35-37]. Improving the intubation conditions with remifentanil, even without use of muscle relaxants, is explained by the fact that the opioids block afferent nerve impulses which are result of the stimulation of pharynx, larynx and trachea during the intubation and cuff insufflation [33].

Hemodynamic parameters after the third measurement $\left(\mathrm{HD}_{2}\right)$ did not differ significantly between groups, however, the difference was significant between control measurements. Hemodynamic parameters after the third measurement were significantly different compared to the second control measurement. The time interval between these two measurements was about 4 minutes (injection of induction agents + calibration of acceleromyograph + stabilization of the control response + injection of the muscle relaxant +30 seconds after). Based on this, we can conclude that during this period the hemodynamic parameters have become baseline, and this difference could be attributed to substantial variations after the administration of propofol and remifentanil $\left(\mathrm{HD}_{1}\right)$. Systolic blood pressure and heart rate did not differ significantly among the different groups 30 second after the administration of rocuronium-bromide, which coincides with the data from literature [38, 39]. 
Neuromuscular blockers can influence the hemodynamic parameters acting on muscarinic receptors, increasing release of norepinephrine or blocking of its reuptake or releasing of histamine [40]. Most studies have shown that rocuronium does not affect the histamine release as well as that it provides hemodynamic stability, while some of them suggest that it has a little influence on histamine release, but only in higher doses [41]. However, the dose of $0.6 \mathrm{mg} / \mathrm{kg}$ shows no significant effects on cardiovascular system, as well as the dose of $0.9 \mathrm{mg} / \mathrm{kg}$ [42]. But, a dose of $1.2 \mathrm{mg} / \mathrm{kg}$ could act vagolytic and lead to tachycardia [43]. From these data we can conclude that the dose used in our study were not able to influence the changes of hemodynamic parameters between the groups.

In the CL group, significant differences in blood pressure compared to the other two groups after the fourth control measurement and 30 seconds after the intubation were recorded. The values of hemodynamic parameters in $\mathrm{CL}$ group were greater after the fifth measurement ( 2 minutes after intubation) with respect to the other two groups. Also, there were statistically significant differences in hemodynamic parameters in relation to the other two groups. So, we can conclude that the use of subjective monitoring of neuromuscular blockade potentiates the response of the cardiovascular system in the form of an increase in blood pressure and heart rate. Although some studies have shown that rocuronium can lead to similar effects, the doses used in those studies were far greater than the dose we used in ours, so in our case the disorder of cardiovascular stability could not be related to the use of rocuronium.

\section{Conclusion}

Based on our results and reviews of the available data, we can conclude with certainty that intubation time is significantly shorter when the subjective monitoring of NMB is used. Also, the hemodynamic response to intubation, which includes the rise of blood pressure and heart rate is much less pronounced in patients in whom the acceleromyography monitoring is used.

Limitations of the study are small number of patients and that we didn't use a mechanomyography which is a gold standard for neuromuscular monitoring.

\section{ACKNOWLEDGMENTS}

The author(s) received no financial support for the research, authorship, and/or publication of this article; Thanks to all the peer reviewers and editors for their opinions and suggestions.

\section{CONFLICT OF INTEREST}

The authors whose names are listed immediately below certify that they have NO affiliations with or involvement in any organization or entity with any financial interest (such as honoraria; educational grants; participation in speakers' bureaus; membership, employment, consultancies, stock ownership, or other equity interest; and expert testimony or patent-licensing arrangements), or nonfinancial interest (such as personal or professional relationships, affiliations, knowledge or beliefs) in the subject matter or materials discussed in this manuscript.Author names: Radmilo Jankovic, Milena Stojanovic, Danica Markovic, Vladan Cvetanovic, Anita Vukovic, Aleksandar Nikolic, Ines Veselinovic, biljana Stosic.

\section{FUNDING INFORMATION}

This research received no specific grant from any funding agency in the public, commercial, or not-for-profit sectors.

\section{REFERENCES}

[1] Amin AM, Mohammad MY, Mona FI. Comparative study of neuromuscular blocking and hemodynamic effects of rocuronium and cisatracurium under sevoflurane or total intravenous anesthesia. M.E.J Anesth. 2009; 20:39-51.

[2] Wang, Yu M, Ochani M, Ann Amella C, Tanovic M, Susarla S, Li JH, et al. Nicotinic acetylcholine receptor alpha 7 subunit is an essential regulator of inflammation. Nature. 2003;421:384-8

[3] Jonsson M, Gurley D, Dabrowski M, Larsson O, Johnson EC. Distinct pharmacologic properties of neuromuscular blocking agents on human neuronal nicotinic acethylcholine receptors: a possible explanation for the train of four fades. Anesthesiology. 2006;105:52133

[4] Sardesai AM, Griffiths R. Monitoring techniques: neuromuscular blockade. Anesth Intensive Care Med. 2005;6: 198-200.

[5] MenckeT, Echternach M, Plinkert PK, Johann U, Afan N, Rensing H, et al. Does the timing of tracheal intubation based on neuromuscular monitoring decrease laryngeal injury? A randomized, prospective, controlled trial. Anesth Analg. 2006;102:306-12.

[6] Grayling M, Sweeney BP. Recovery from neuromuscular blockade: a survey of practice. Anaesthesia. 2007;62: 806-9.

[7] Della Rocca G, Iannuccelli F, Pompei L, Pietropaoli P. Reale C, Marco P.Di, Neuromuscular block in Italy: A survey of current management. Minerva Anestesiol. 2012;78:767-73.

[8] Gotiwale K, Lele S, Setiya S. Stress response to laryngoscopy and ease of intubation:comparison between Macintosh and (levering) McCoys type laryngoscope. Int J Res Med Sci. 2016;4:3141-5.

[9] Chien-Wei Cheng, Yi-Ming Weng, Chih-Chuan Lin, Ching-I Kuo, Chi-Chun Lin. The effects of post-intubation hypertension in severe traumatic brain injury. Signa Vitae. 2013;8: 24-9.

[10] Nandi R, Basu SR, Sarkar S, Garg R. A comparison of haemodynamic responses between clinical assessment-guided tracheal intubation and neuromuscular block monitoring-guided tracheal intubation: A prospective, randomised study. Indian J Anaesth. 2017;61:910-5.

[11] Witkowska M, Karwacki Z, Wierzchowska J, Bukowski P. Neuromuscular block monitoring for optimisation of conditions for endotracheal intubation. Anestezjol Intens Ter. 2009;41:140-4

[12] Fuchs-Buder T, Claudius Scovgaar LT, Eriksson LI, Mirakhur LK, Viby-Mogensen J. 8th International Neuromuscular Meeting. Good clinical research practice in pharmacodynamic studies of neuromuscular blocking agents II: the Stockholm revision. Acta Anaesthesiol Scand. 2007;51:789-808.

[13] Mayer M, Doenicke A, Hofmann A, Peter K. Onset and recovery of rocuronium (ORG9246) and vecuronium under enflurane anesthesia. Br J Anesthesia. 1992;69:511-2.

[14] Bartowski RR, Witkowski TA, Azad S, Lesin J, Marr A. Rocuronium onset of action: A comparison with atracurium and vecuronium. Anesth Analg. 1993;77:574-8.

[15] Donati F, Meistelman C. A kinetic-dynamic model to explain the rela- 
tionship between high potency and slow onset time for neuromuscular blocking drugs. J Pharmacokinet Biopharm. 1991;195:537-52.

[16] Donati F. Onset of action of relaxants. Can J Anaesth. 1988;35:S52S58.

[17] Wierda JKMH, de Wit APM, Kuizenga K, Agosoon S. Clinical observations on the neuromuscular blocking action of Org9426, a new steroidal non-depolarizing agent. Br J Anesth. 1990;64:521-3.

${ }^{[18]}$ Folders FF, Deery A. Protein binding of atracurium and other shortacting neuromuscular blocking agents and their interaction with human cholinesterases. Br J Anaesth. 1983;55:31S-34S.

[19] Bevan DR. Rocuronium. J Crit Care. 1995;14:257-63.

[20] Hans P, Brichant JF, Hubert B, Dewandre PY, Lamy M. Influence of induction of anaesthesia on intubating conditions one minute after rocuronium administration: comparison of ketamine and thiopentone. Anaesthesia. 1999;54:276-9.

[21] Fuchs-Buder T, Sparr HJ, Ziegenfuss BT. Thiopental or etomidate for rapid sequence induction with rocuronium. $\mathrm{Br} \mathrm{J}$ Anaesth. 1998;80:504-6.

[22] Ganidagli S, Cengiz M, Baysal Z. Effect of ephedrine on the onset time of succinylcholine. Acta Anaesthesiol Scand. 2004;48:1306-9.

[23] Albert F, Hans P, Bitar Y, Brichant JF, De-Wandre PY, Lamy M. Effects of ephedrine on the onset time of neuromuscular block and intubating conditions after cisatracurium: preliminary results. Acta Anaesthesiol Belg. 2000;51:167-71.

[24] Harrison P, Feldman SA. Intubating conditions with ORG NC 45. Anaesthesia. 1981;36:874-7.

[25] Singh K, Singhal S, Raghove P. A study to evaluate effect of ephedrine on intubating conditions and haemodynamic parameters using low dose rocuronium with different induction agents. Int J Pharmacol Clin Sci. $2013 ; 2: 9-13$.

[26] Mirakhur RK. Dose-response and time-course of action of rocuronium bromide. Eur J Anaesthesiol. 1995;11: 23-5.

[27] Kayhan Z, Aldemir D, Mutlu H, Öğüş E. Which is responsible for the haemodynamic response due to laryngoscopy and endotracheal intubation? Catecholamines, vasopressin or angiotensin? Eur J Anaesthesiol. 2005;22:780-5.

${ }^{[28]}$ Stoelting RK. Circulatory changes during direct laryngoscopy and tracheal intubation. Anesthesiology. 1977;47: 381-4.

[29] Singhal SN. Haemodynamic response to laryngoscopy andintubation: Comparison Of McCoy And MacintoshLaryngoscope. The Internet Journal of Anesthesiology. 2007;17:1-5.

[30] Cozanitis DA, Nuuttila K, Merrett JD, Kala R. Influence of laryngoscope design on heart rate and rhythm changes during intubation. Can Anesth Soc. 1984;31:155-9.

[31] Singh S, Laing EF, Owiredu WKBA, Singh A. Comparison of esmolol and lidocaine for attenuation of cardiovascular stress response to laryngoscopy and endotracheal intubation in a Ghanaian population. Anesth Essays Res. 2013;7:83-8.

[32] Egan TD, Minto CF, Hermann DJ, Barr J, Muir KT, Shafer SL. Remifentanil versus alfentanil: comparative pharmackinetics and pharmacodynamics in healthy adult male volunteers. Anesthesiology.
1996;84:821-33

[33] Cros AM, Lopez C, Kandel T, Sztark F. Determination of sevoflurane alveolar concentration for tracheal intubation with remifentanil, and no muscle relaxant. Anesthesia. 2000;55:965-9.

[34] Hogue CW, Bowdle TA, O’Leary C, Duncalf D, Miguel R, Pitts $\mathrm{M}$, et al.A Multicenter evaluation of total intravenous anesthesia with remifentanil and propofol for elective inpatient surgery. Anesth Analg. 1996;83(2):79-85.

[35] Scott LJ, Perry CM. Remifentanil: a review of its use during the induction and maintenance of general anesthesia. Drugs. 2005;65:1793-823

[36] Ezri T, Szmuk P, Warters RD, Gebhard RE, Pivalizza EG, Katz $\mathrm{J}$. Changes in onset time of rocuronium in patients pretreated with ephedrine and esmolol - the role of cardiac output. Acta Anaesthesiol Scand. 2003;47:1067-72

[37] Tan CH, Onisong MK, Chiu WKY. The influence of induction technique on intubating conditions 1 minute after rocuronium administration: a comparison of propofol-ephedrine combination and propofol. Anaesthesia. 2002;57:223-6.

[38] Stevens JB, Hecker RB, Talbot JC, Walker SC. Haemodynamic effects of rocuronium and vecuronium are different during balanced anaesthesia. Acta Anaesthesiol Scand. 1997;41:502-5.

[39] Hudson ME, Rothfield KP, Tullock WC, Firestone LL. Hemodynamic effects of rocuronium bromide in adult cardiac surgical patients. Canadian J Anaesth. 1998;45:139-43.

[40] Rao U. Comparison of hemodynamic and neuromuscular properties of rocuronium versus vecuronium in anesthesia. Int J Med Sci Public Health. 2016;5:1617-20.

[41] Levy JH, Davis GK, Duggan J, Szlam F. Determination of the hemodynamics and histamine release of rocuronium (Org 9426) when administered in increased doses under $\mathrm{N} 2 \mathrm{O} / \mathrm{O} 2$-sufentanil anesthesia. Anesth Analg. 1994;78:318-21.

[42] Savargaonkar AP, Ruparel DH, Patil RS. Comparison of effects of rocuronium bromide versus vecuronium bromide on hemodynamic parameters during anaesthesia for elective surgical procedures. Int J Basic Clin Pharmcol. 2016;5:317-23.

[43] Naguib M, Kopman A, Cynthia AL, Hunter J, Lopez A, Brull SJ. A survey of current management of neuromuscular block in the United States and Europe. Anesth Analg. 2010;111:110-9.

How to cite this article: Radmilo J. Janković, Milena D. Stojanović , Danica Z. Marković , Vladan A. Cvetanovic , Anita Z.Vuković , Aleksandar N.Nikolić. et al. Impact of different stimulation patterns of neuromuscular blockade monitoring and clinical assessment on intubation time and intensity of hemodynamic response during rocuronium induced endotracheal intubation. Signa Vitae. 2020;16(1):79-88. doi:10.22514/sv.2020.16.0011. 